Int. J. Electrochem. Sci., 13 (2018) $1859-1868$

International Journal of

ELECTROCHEMICAL

SCIENCE

www.electrochemsci.org

\title{
An Electrochemical Sensor for Determination of Ceftazidime Based on Poly (crystal violet) Doped Platinum Nanoparticles Modified Electrode
}

\author{
Yanli Sun, Xin Li, Xueliang Wang ${ }^{*}$, Zhangyu Yu, Tao Wang ${ }^{*}$ \\ Department of Chemistry and Chemical Engineering, Heze University, Heze 274015, People's \\ Republic of China \\ *E-mail: yuzywxl@163.com
}

doi: $10.20964 / 2018.02 .25$

Received: 2 October 2017 / Accepted: 1 December 2017 / Published: 28 December 2017

\begin{abstract}
An electrochemical sensor for determination of ceftazidime (CFD) was fabricated by polymerizing crystal violet (PCV) and platinum nanoparticles (nanoPt) on a glassy carbon electrode (GCE). The nanoPt/PCV composite film exhibited excellent catalytic performance toward CFD. On this modified electrode, the CFD had an irreversible oxidation peak at $0.8 \mathrm{~V}$ with a dramatically amplified current value. The electrochemical behaviors of CFD and the conditions that may affect these behaviors were investigated detailedly on the nanoPt/PCV/GCE. Under the optimized conditions, the sensor showed a wide linear range over the concentration of CFD from 0.25 to $10 \mu \mathrm{M}$. The detection limit was 0.01 $\mu \mathrm{M}$. The sensor can be applied for detecting the content of CFD in meat samples with good selectivity and stability. The recovery was between $97.8 \%$ and $103 \%$.
\end{abstract}

Keywords: Electrochemical sensor; Ceftazidime; Crystal violet; Pt nanoparticle; Application

\section{$\underline{\text { FULL TEXT }}$}

(C) 2018 The Authors. Published by ESG (www.electrochemsci.org). This article is an open access article distributed under the terms and conditions of the Creative Commons Attribution license (http://creativecommons.org/licenses/by/4.0/). 